\title{
Is fluency being 'neglected' in the classroom? Teacher understanding of fluency and related classroom practices
}

Article

Accepted Version

Tavakoli, P. and Hunter, A.-M. (2018) Is fluency being 'neglected' in the classroom? Teacher understanding of fluency and related classroom practices. Language Teaching Research, 22 (3). pp. 330-349. ISSN 1477-0954 doi: https://doi.org/10.1177/1362168817708462 Available at https://centaur.reading.ac.uk/70038/

It is advisable to refer to the publisher's version if you intend to cite from the work. See Guidance on citing.

To link to this article DOI: http://dx.doi.org/10.1177/1362168817708462

Publisher: Sage

All outputs in CentAUR are protected by Intellectual Property Rights law, including copyright law. Copyright and IPR is retained by the creators or other copyright holders. Terms and conditions for use of this material are defined in the End User Agreement.

www.reading.ac.uk/centaur 
Central Archive at the University of Reading

Reading's research outputs online 
Authors: Dr Parvaneh Tavakoli, University of Reading

Ann-Marie Hunter, St Mary's University College

\title{
Is fluency being 'neglected' in the classroom?
}

\section{Teacher understanding of fluency and related classroom practices}

\begin{abstract}
This paper reports on a study examining second language (L2) teachers' understanding of speech fluency and their self-reported classroom practices for promoting it.

Qualitative and quantitative data collected from 84 L2 teachers in England were analysed to answer the research questions. In addition to the descriptive statistics and lexical frequency analysis used to explore teacher understanding of fluency, Rossiter, Derwing, Manimtim and Thomson's (2010) framework was employed to analyse the teachers' reported classroom practices. The results suggest that teachers often define fluency in a broad sense, with many using fluency and speaking ability interchangeably. Similarly, a large majority of the activities reported by the teachers were useful for enhancing speaking practice rather than focussing on fluency specifically. The findings underline the interaction between teacher understanding of fluency and their classroom practice (Borg, 2003), and highlight a mismatch between what fluency research recommends and what teachers do in class. Though the study highlights the complex and multifaceted nature of L2 oral fluency, we argue that adopting a narrower and more focused definition of fluency could help teachers take a more active and practical approach to promoting it in the classroom.
\end{abstract}

Key words: fluency, speaking ability, classroom practice

\section{Introduction}

There is little disagreement among second language (L2) teachers and researchers that many L2 learners hope to become competent and fluent speakers of the language they are learning. As such, a considerable amount of research has been carried out to understand what constitutes fluent speech (Derwing, Munro, Thomson, \& Rossiter, 2009; Freed, 2000; Lennon, 1990; Segalowitz, 2010) and how it can be achieved (Freed, 2000; Lennon, 1990; Koponen \& Riggenbach, 2000). From a research perspective, 
fluency is an important research focus as it not only characterises one of three key features of oral performance, i.e. complexity, accuracy and fluency (Ellis, 2009; Housen, Kuiken \& Vedder, 2012; Skehan, 2009), but also because it is a reliable predictor of L2 proficiency (de Jong, Steinel, Florijn, Schoonen \& Hulstijn, 2012; Révész, Ekiert \& Torgersen, 2016) and shines light on underlying processes of speech production and language acquisition (e.g. proceduralisation) (De Jong et al., 2012; Kormos, 2006; Segalowitz, 2010). However, it has been suggested that fluency is a complex construct to define (e.g. Freed, 2000), and a difficult aspect of oral performance to assess (Brown, 2006; Fulcher, 2003) and while L2 research has underlined the importance of fluency, it has remained a less attended-to area in L2 teaching (Lennon, 1990; Freed, 2000; Rossiter et al., 2010). This may, at least partly, be related to the commonly-held assumption that fluency develops naturally as general proficiency progresses, and that therefore it cannot be 'taught' (Chambers; 1997; Lennon, 1990). Alternatively, it is possible that fluency is not being tackled in the classroom due to the fact that its complex, multifaceted nature makes it difficult for teachers to engage with at both conceptual and practical levels.

Nearly three decades ago, Gatbonton and Segalowitz (1988), in a then pioneering and novel approach to bringing research and practice together, drew on fluency research findings and proposed a "creative automatization process" by which L2 learners could "develop the automaticity component of fluency in second language production in a classroom setting" (p. 473). The principal rationale for the proposal in their article was that, although fluency is normally assumed to develop gradually with the development of L2 proficiency and through exposure and practice inside and outside classroom, there are classroom activities that can help develop automaticity and fluency in a communicative manner.

Since the publication of Gatbonton and Segalowitz's (1988) study, there have been great developments in terms of how L2 fluency is conceptualised and defined (Kahng, 2014; Kormos, 2006; Segalowitz, 2010, 2016; Skehan, 2009); how fluency is measured (Skehan, 2003; Tavakoli, 2016; Tavakoli \& Skehan, 2005), how technology can help measure fluency accurately (Boersma \& Weenink, 2008; de Jong et al, 2009) and there have been many suggestions as to how research findings can relate to L2 teaching practice (de Jong \& Perfetti, 2011; Foster \& Hunter, 2016; Tavakoli, Campbell $\&$ McCormack, 2016). Foster (2009) and others have argued that SLA research should be complemented by feedback and input from the teaching community and yet, despite 
the growing body of research on L2 fluency, we know very little about how teachers understand L2 fluency and in what ways their understanding of fluency interacts with their classroom practices. This is a gap the current study aims to help fill.

\section{Fluency from a research perspective}

Fluency is a term that is used both in a 'broad' and a 'narrow' sense (Lennon, 1990). In the English language and in a broad sense of the term, fluency is often used to represent 'mastery' of the language, and reflects what is sometimes termed 'general proficiency' in language teaching and testing. In this broad sense, although it can be used to refer to the skills of reading, writing or speaking, fluency is normally used in reference to "spoken command of a foreign language" (Lennon, 1990: 389). In a narrow sense of the term, and that which is often used by language specialists and L2 researchers, the term reflects a key characteristic of speaking ability and mainly refers to ease and automaticity of speech. In this sense, fluency is only one of the several aspects of speaking ability, and differs from other characteristics such as grammatical accuracy and syntactic complexity. In this narrow sense, for example, Lennon (1990: 390) defined fluent speech as that which is "unimpeded by silent pauses and hesitations, filled pauses ("ers" and "erms"), self-corrections, repetitions, false starts, and the like". For the purpose of this paper, we consider Koponen and Riggenbach's (2000) definition of fluency as "flow, continuity, automaticity, or smoothness of speech" (Koponen \& Riggenbach, 2000, p. 6) a useful and practical one to begin with. Conscious of the distinction between the two, we will not use fluency and proficiency interchangeably in this paper.

In order to understand fluency, it is necessary to look at the speech production process. Levelt (1989) described the first language (L1) speech production process in terms of three main stages of conceptualising the intended message, formulating a preverbal message and articulating speech. L2 researchers examining fluency, have adapted this model to describe L2 speech (de Bot, 1992; Kormos, 2006; Segalowitz, 2010) and they highlight some important differences between L1 and L2 production processes. The main difference, they argue, is that in L1 much of the mechanics of speech construction is automatic and happens in a parallel-processing fashion, whereas in L2 processing, especially in earlier stages of language acquisition, speech production is not yet automatic and the different processes may not happen in parallel. The lack of 
automaticity and parallel processing, makes the speech production process more intensive, resulting in overt speech which is slower, and characterised by more frequent pauses and hesitations, particularly in the middle of clauses (de Jong, 2016).

Drawing on Levelt's model and in an attempt to develop a framework for understanding fluency, Segalowitz (2010) suggested that there are three aspects of fluency: Cognitive, utterance and perceived. Cognitive fluency is a term which relates to the speed and manner of the underlying mechanics of speech production; perceived fluency refers to the particular reaction from listeners about the cognitive fluency of the speaker; and utterance fluency, the measurable aspects of speech fluency which reflect the cognitive fluency underlying speech production. Although the distinction between the three aspects of fluency is important for language teaching purposes, for reasons of scope we will not discuss such distinctions in this paper.

From a research perspective, the study of utterance fluency, with its amenability to quantitative research, has attracted substantial interest. Lennon (1990) was one of the first researchers calling for a systematic and objective approach to measuring fluency. Skehan (2003) and Tavakoli and Skehan (2005) proposed a framework for representing and measuring oral fluency, or what Segalowitz has since called utterance fluency. This framework consists of three sub-constructs of speed, breakdown and repair measures. Speed fluency measures are those features of speech that demonstrate the speed of delivery (e.g. articulation rate); breakdown measures indicate a disruption in the flow of speech (e.g. pauses); and repair measures reflect the monitoring process and repair strategies associated with it during the speech production process (e.g. repetitions; reformulations).

The brief discussion above suggests that research in this area has managed, at least to some extent, to analyse the complex construct of fluency by dividing it into separate aspects (e.g. utterance fluency) and sub-constructs (e.g. speed, breakdown, repair). Although there are limitations to conceiving of fluency in this very focused way, this approach to understanding fluency has provided objective frameworks that allow for a more systematic observation and measurement of fluency (e.g. Skehan, 2003; Tavakoli \& Skehan, 2005). Research in this area has provided pedagogic recommendations that can be used to enhance fluency in classroom. We turn now to an overview of fluency research in L2 teaching. 


\section{Fluency in L2 teaching}

Fluency research has been prolific in recent years, generating a great many findings that are of direct relevance and potential benefit to L2 teaching in different instructional settings, e.g. schools, colleges and universities (Kormos \& Dénes, 2004; Mehnert, 1998; Foster \& Tavakoli, 2009), in different learning contexts, e.g. Study Abroad, At Home, and non-instructional contexts (Freed, Segalowitz \& Dewey, 2004; Mora \& Valls-Ferrer, 2012), and for learners of different languages, e.g. English, Dutch, French, and Chinese (Derwing, et al., 2009; de Jong et al., 2012; Préfontaine, 2013). In what follows we summarise the classroom activities and practices that L2 fluency research has consistently reported to have positive effects on fluency.

Formulaic sequences. Wray (2000; 2002; 2008) and Wood (2010; 2016) have reported on the positive impact of explicit instruction of formulaic sequences on L2 fluency development. The findings have consistently shown that practising use of formulaic sequences promotes fluency.

Pre-task planning time. A large number of studies have reported that fluency is positively affected when learners are given the opportunity to plan before they perform a task (e.g. Mehnert, 1998; Foster \& Skehan, 1996; Tavakoli \& Skehan, 2005). The benefits of pre-task planning can increase by manipulating the length of time (Mehnert, 1998), and by training learners on how to use the planning time (Mochizuki \& Ortega, 2008).

Task repetition. The effects of repeating a communicative task has been found to increase fluency of oral performance. Although task design and methodology, as well as the task itself, have varied considerably between studies, fluency has consistently been found to improve when the same task is repeated (e.g. Wang, 2014; Lynch \& Maclean, 2000; Gass et Al, 1999; Ahmadian \& Tavakoli, 2011; Sample \& Michel, 2014).

4/3/2 technique. The 4/3/2 technique refers to a classroom activity which involves task repetition with increasing time pressure, i.e. learners are required to speak on a chosen topic for 4, then 3, and finally 2 minutes. Several studies including de Jong and Perfetti (2011), Nation (1989), and Boers (2014), among others, have reported positive benefits of the $4 / 3 / 2$ technique on fluency.

Awareness-raising activities. Although less research has been carried out examining the effects of awareness-raising (Seifoori \& Vahidi, 2012; Tavakoli et al., 2016) on 
learner fluency, the existing evidence suggests that raising learner awareness about the characteristics of fluent speech (e.g. by listening to and commenting on native speakers' performance of a task) can help promote fluency. The awareness-raising activities can be complemented by strategy-training, i.e. training learners to use filled-pauses, lexical fillers, and lexical chunks (Tavakoli et al., 2016).

Our reading suggests that Gatbonton and Segalowitz's (1988) paper was one of the earliest attempts to link research findings in the area of L2 fluency with L2 classroom practice. Arguing for "a rightful place for the promotion of automaticity fluency skills" (p. 489) in L2 teaching, the authors contended that communicative language teaching syllabi would be limited if fluency-focused activities were not included. In a later study, Gatbonton and Segalowitz (2005) further highlighted the importance of fluency in language use and criticised the lack of a communicatively useful practice in L2 teaching methodologies to promote fluency. They maintained that "there are no provisions in current CLT methodologies to promote language use to a high level of mastery through repetitive practice" (Gatbonton \& Segalowitz, 2005; p. 327). Conducting a review of teaching materials available to language teachers in an ESL context, Rossiter et al. (2010) reported that there was a heavy emphasis on 'free communication' activities in the course books they reviewed. They argued that although free communication activities are popular in ESL teaching, there is little research evidence to suggest they can help promote L2 fluency. Diepenbroek and Derwing (2014) surveyed 48 textbooks used for ESL and Language Instruction for Newcomers to Canada (LINC) courses and, similarly, found that they were "not very useful for the development of oral fluency" (p. 16). The authors suggested that this could explain, at least to some extent, why LINC students often made little or no progress in speaking ability. In sum, the studies reported here suggest that the recent development in fluency research and the multitude of pedagogic implications this body of research has offered has had little impact on the way fluency is presented in L2 teaching materials. However, while fluency-focused activities may be lacking in coursebooks and training materials, it does not necessarily follow that it is therefore 'neglected' it the classroom. As Foster and Hunter (2016) and Tomlinson (2016) point out, teachers are not slaves to their coursebooks and are able to adapt exercises or design new activities for different purposes. In order to explore any potential gap between L2 research and L2 practice (Borg, 2009; Nassaji, 2012; Tavakoli, 2015), it is therefore necessary to explore teachers' understanding of L2 fluency and the practices they use to promote fluency in the classroom. The following research questions guided the study: 
1) What does L2 speech Fluency mean to language teachers?

1a) How do L2 teachers define fluency?

1b) How confident are they in promoting fluency in classroom?

1c) How familiar are they with research findings in L2 fluency?

2) How do language teachers promote fluency in classroom?

\section{Methodology}

To address the research questions, quantitative and qualitative data were collected from 84 L2 teachers using a questionnaire. The details are provided below.

\section{Participants}

A convenience sampling approach to data collection was used as the data were collected before the start of four Continuing Professional Development (CPD) workshops which participants were attending in England during the 2015-16 academic year. The participants reported in this study were 84 L2 teachers who were teaching either English as a foreign or second language (henceforth EFL) or Modern Foreign Languages (henceforth MFL) at the time of data collection. Of the total number of the teachers, $49 \%$ were EFL and 51\% MFL teachers. The MFL teachers taught Spanish, Italian, German and French. A small number of the MFL teachers, 7\%, taught more than one foreign language. In terms of qualifications, they came from a range of different backgrounds with $17.9 \%$ of them having completed only an initial teacher training qualification at a certificate level (e.g. CELTA), while the rest had completed more advanced teacher training programmes at diploma or graduate levels. They all had a minimum of a first degree, and at least three months of teaching experience when they attended the CPD workshops. $32 \%$ of the teachers were teaching at primary and secondary schools, $22.7 \%$ at private and state-funded colleges, and $45.2 \%$ at university language centres. In terms of experience, $9.5 \%$ had less than a year, $20.2 \%$ less than 5 years, $19 \%$ between 5 and 10 years, and $51.2 \%$ more than 10 years of teaching experience. The participants came from a range of different first languages and nationalities. Informed consent was sought from the participants, and all ethical issues including anonymity and confidentiality were adhered to. 


\section{Questionnaire}

The instrument used in this study was a questionnaire, eliciting both quantitative and qualitative data. Since this is one of the first studies investigating teachers' understanding of and practices in fluency, there was little previous research to draw on for the purpose of developing a questionnaire. A few studies (e.g. Brown, 2006; Galaczi, Lim \& Khabbazbashi,; 2013; Préfontaine, 2013; Préfontaine and Kormos, 2016) have examined perceptions of fluency by asking raters or expert judges to listen to L2 speech samples and rate different aspects of the speakers' fluency. Such studies are often aimed at examining perceived fluency (Préfontaine, 2013) or validating fluency assessment practices (Brown, 2006; de Jong et al., 2012; Galaczi et al., 2013). To the best of our knowledge, Dore (2015) is the only recent study that used a questionnaire to examine teacher definitions and perceptions of fluent L2 speech. In Dore's questionnaire, the qualitative section asked the teachers to listen to three L2 speech samples, list characteristics of fluent speech, and describe what fluency means. Following Freed (2000), the qualitative section of Dore's (2015) questionnaire asked the teachers to rate, on a 5-point semantic differential scale, the degree of the contribution different aspects of language performance, e.g. speed, pausing, grammar, vocabulary and pronunciation make towards fluency. We were not interested in teachers' judgements of fluency and therefore did not ask the participants to rate speech samples. Rather, we were keen to learn more about how teachers understood fluency and how they promoted it in their teaching.

There were six sections in our questionnaire, and the questions' formats were short-answer, open-ended descriptive, and Likert scale items. While Section 1 asked the teachers to provide the main characteristics of fluent L2 speech, Section 2 asked them to complete the following sentence "A fluent L2 speaker is someone who ....". They could answer the questions in as much detail as they wanted. Section 3 included a number of Likert-scale items asking questions about their understanding of fluency, their familiarity with research in this area and their confidence in promoting fluency in their class.

Given our interest in teachers' classroom practices, Section 4 aimed at eliciting three examples of activities and/or tasks teachers used to promote fluency in classroom. Section 5 asked them for their views on the importance of promoting fluency. The last section of the questionnaire elicited demographic data including information about their teaching context, length of teaching experience, and academic and professional 
qualifications, but the analysis of this set of data is not reported in this paper. The questionnaire was piloted with 5 teachers before it was finalised and used in the study.

\section{Analysis and results}

In order to answer the research questions, a number of quantitative and qualitative analyses were run. Details of the data analyses for each question are discussed below.

\section{Research question 1: What does L2 fluency mean to language teachers?}

In this section, the results are summarised in relation to the three sub-questions of a) how teachers define fluency, b) how confident they are in promoting fluency in classroom, and c) how familiar they are with research in L2 fluency.

\section{a. How do teachers define fluency?}

In order to explore how teachers define fluent speech in the data, two different analyses are presented here. First, descriptive statistics for the quantitative data is provided.

\section{Insert Table 1 here.}

As indicated in Table 1, while $16.7 \%$ of the teachers reported a limited or no knowledge of fluency, more than $80 \%$ of the teachers reported they knew what speech fluency means either to a large or to some extent. The teachers reported lower confidence when they were asked whether they knew what factors contributed to fluency. A relatively large number of the teachers, $(11.9 \%$ and $59.5 \%)$, reported that they knew to a large extent and to some extent respectively what factors contributed to fluency, with $28.6 \%$ acknowledging their knowledge was limited or non-existent.

In addition to the Likert-scale questions, the questionnaire included two sections eliciting qualitative data about how teachers understood L2 fluency. The questions asked the participants a) "what are the main characteristics of fluent L2 speech", and b) "complete the following statement: A fluent L2 speaker is someone who ....". The responses provided us with a small corpus of about 6100 words in which the teachers characterised and defined fluent speech. To analyse the data, after transcribing them we ran a frequency analysis to identify the most recurring words and lexical chunks used to define fluency in the data. The frequency analysis identified 452 items that were repeated in the data. We then took a bottom-up approach to categorising the 452 items identified in the frequency analysis. Finally, we examined the data qualitatively to 
identify any words or chunks that were used to define fluency but may have not been captured by the frequency analysis. To ensure reliability of the coding procedure, we took an inter-rater coding approach. The first researcher categorised the data into four main themes initially. Then, the second researcher coded $20 \%$ of the data. While the results of the second coding showed a full agreement between the two coders about the four categories, there was some disagreement, about $15 \%$, in classifying definitions within the four themes. The disagreements were further discussed until resolved. The whole data set was checked again before $10 \%$ of the data was coded for a second time. This time a higher agreement rate of $92 \%$ was achieved. The coding process resulted in four main categories of fluency definitions and/or characteristics. Table 2 below shows the main categories as well as the frequencies, percentages, and examples for each category.

Insert Table 2 here.

As shown in Table 2, the first category included terms that define fluency in a focused and narrow sense of the term, i.e. terms often used by L2 researchers and language specialists to indicate flow, continuity and automaticity. Examples in this category, often referring to the three aspects of utterance fluency, i.e., speed, breakdown and silence, included lack of hesitations (33), lack of pauses (28), and speed, flow and fluidity of speech (20). It should be noted that items in this category had a relatively low frequency and comprised only $13.4 \%$ of the 452 items. The second category, which comprises the largest proportion of the data (43.8\%), represented concepts aimed at defining speaking ability rather than fluency. This category went beyond measures of utterance fluency to conceptualise fluency as a global indicator of the spoken ability. The most frequently mentioned items in this category included speaking confidently (56), ability to communicate (31), correct or intelligible pronunciation (including accent), intonation and prosody (30), speaking like a native speaker (29), conveying the intended meaning / message (20), speaking at ease (14), appropriacy of use of language (13), and colloquial and conversational use of language (5). The third category contained terms and concepts that referred to the overall L2 proficiency. Interestingly, some of the concepts in this category were of very high frequency. The most frequently-occurring terms were correct use of grammar (63), a wide range of vocabulary (and lexical items) (61), being confident (10), ability to paraphrase or say the same thing in alternative ways (8), and thinking in the L2 (5). We note, however, that given the central role of grammar 
and vocabulary in language use and communication, it is equally possible to assume that responses such as correct use of grammar and a wide range of vocabulary were referring to speaking ability (i.e 'accuracy' and 'complexity' in oral performance). Finally, about $10 \%$ of the items used to define fluency were either vague (e.g. ability to listen to mass media) or uninformative (e.g. being fluent) and hence difficult to categorise; these were placed in a fourth category as indicated on Table 2.

\section{b. How confident are teachers in promoting fluency?}

Five questions asked teachers about their confidence in promoting L2 learners' fluency in classroom. Descriptive statistics was used to analyse the data. The results are presented in Table 3 below.

Insert Table 3 here.

As can be seen in Table 3, the participants' self-reported knowledge of and confidence about promoting fluency in classroom were divided. While $52.4 \%$ reported at least some knowledge of teaching fluency in classroom, 47.6\% suggested they had limited or very little knowledge of this. The figures are similar for other questions where a relatively large number of teachers, i.e. $44.1 \%, 41 \%$ and $39.3 \%$, reported limited or hardly any confidence in helping learners, using activities or learning strategies that promote fluency respectively. When asked the question in a more general sense, the participants expressed more confidence about helping their learners improve fluency with $69 \%$ of the teachers choosing to some extent or to a large extent choices.

\section{c. How familiar are teachers with research findings in L2 fluency?}

The descriptive analysis of the quantitative data on teachers' familiarity with fluency research is presented on Table 4 below.

Insert Table 4 here.

As indicated in Table 4, while 59.5\% of the participants reported some familiarity, more than $40 \%$ of the teachers reported limited or hardly any familiarity with fluency research findings. It is interesting, however, to see that a larger proportion of the teachers, i.e. $72.6 \%$ thought that fluency research at least to some extent can help them with their classroom practice.

\section{Research question 2: How do teachers promote fluency in classroom?}


When asked to provide three examples of activities they use in classroom to promote L2 fluency, the participants provided a wide range of activities. Although a large number of the teachers provided three examples, some mentioned one or two. In total, 57 of the 252 slots for providing examples were left blank. There was variety in the amount of details provided for each activity with some just naming the activities whereas others explaining the activities and/or the classroom teaching process in some detail.

To analyse the teachers' responses, we adopted Rossiter et al.'s (2010) framework and extended it to make it more compatible with our data. Rossiter et al.'s (2010) framework divides fluency focused activities into five categories of a) consciousness-raising activities, b) rehearsal and repetition tasks, c) use of formulaic sequences, d) use of discourse markers and lexical fillers, and f) communicative free production activities. Given the existing research evidence on the effectiveness of fluency instruction, summarised above, we propose the following changes to Rossiter's framework. First, pretask planning time activities (Ahmadian, 2012; Tavakoli \& Skehan, 2005) and fluency strategy training (Seifoori \& Vahidi, 2012; Tavakoli et al., 2016) should be added to Rossiter's framework as examples of pedagogic approaches to fluency instruction. Furthermore, we suggest that the use of formulaic sequences, discourse markers and lexical fillers be considered as a single category since it is possible that an item belongs to more than one category. For example, expressions such as "I mean" or "you know" can be labelled as a discourse marker, a formulaic sequence and a lexical filler at the same time. The framework we are suggesting for analysing the pedagogic activities that promote fluency in classroom therefore has the following categories:

a) consciousness-raising activities

b) planning, rehearsal and repetition,

c) use of formulaic sequences, discourse markers \& lexical fillers

d) fluency strategy training

e) communicative free production tasks

In our data, we also came across a relatively large group of activities mentioned by the teachers that could not be classified in any of the five categories discussed above as they were principally aimed at developing skills other than speaking (e.g. reading and listening) or L2 components rather than fluency (vocabulary and pronunciation). We have called this category as general L2 proficiency. Therefore, our analysis framework has a sixth category: 
f) general L2 proficiency

We coded the activities proposed by the teachers against these six categories and calculated the frequency of the activities in each group. There were several disagreements in categorising some of the activities; the disagreements were discussed until a full agreement was achieved. Finally, to ensure reliability of the analysis, a 10\% of the data was second coded and a 91\% agreement was achieved. Table 5 below demonstrates the six categories, their frequencies, percentages and some examples from each category.

\section{Insert Table 5 here.}

As indicated in Table 5, the largest category of the activities proposed by the teachers was the free production activities (53.6) which are aimed at helping learners develop their speaking ability in general. While $22.6 \%$ of the slots were left blank, $13.5 \%$ of the activities were those that help develop other aspects of L2 ability, e.g. reading, listening and vocabulary knowledge, which we consider useful for developing the general L2 proficiency. The percentages for the first four categories were very small, with only a sum of $10.4 \%$ of the total number of the reported activities coming under these headings.

\section{Discussion}

In this section, we discuss the findings of the study in relation to our two research questions. First, as regards "what does L2 fluency mean to teachers", the results of the quantitative analysis showed that teachers reported a relatively high level of confidence in their understanding of fluency, a moderate level of confidence in promoting it in classroom, and a lower level of familiarity with fluency research findings. A lack of consensus was witnessed in how teachers defined fluency, and the analysis indicated that their definitions often differed from those adopted in SLA research. In terms of classroom practices, while the majority of activities reported were aimed at enhancing speaking ability, a smaller proportion were activities that research has shown beneficial for promoting fluency. The results also suggested that a large number of the teachers believed fluency research can help them with their L2 teaching.

Earlier in this paper, and following Lennon's (1990) observation, we referred to the fact that fluency can be described in a narrow or broad sense. However, the qualitative data analysis implied that teachers' definitions of speech fluency are not of a 
dichotomous nature and often seem to inhabit the space somewhere between a broad and narrow definition. Our data analysis suggests that general speaking ability and general L2 proficiency (the two largest categories of responses), are central to teachers' understanding of fluency. However, we are aware that despite adopting a rigorous approach to coding and categorising the definitions of fluency and achieving a high inter-coder agreement of $92 \%$, our analysis is limited in that the two categories may overlap. For example, with the questionnaire-based data we have collected it is difficult to ascertain whether by 'correct grammar' the teachers are referring to a characteristic of speaking ability or general L2 proficiency. Data collected through interviews or focus groups can minimise the overlap and provide clearer categories. Our results also suggested that defining fluency in its narrow sense receives only a relatively small proportion of the teachers' attention. Discussing whether this lack of attention is due to unfamiliarity with narrow definitions of fluency or a disagreement with them goes beyond the scope of the current study. What can be said with a degree of certainty is that the teachers demonstrated an awareness of the underlying cognitive processes involved in language production (e.g. automaticity and ease of processing), and displayed an understanding of the building blocks (e.g. range of vocabulary and correct grammar) needed to facilitate L2 processing demands.

The references the participants made about the role of cultural understanding in fluency highlight Segalowitz's (2016: 91) observation that "fluency is the outcome of the operation of a dynamical system where cognitive, motivational, social, sociolinguistic, pragmatic and psycholinguistic considerations interact in complex ways". The participants' comments on culture are perhaps reminding researchers of the need to expand fluency research beyond the study of utterance fluency measures to explore social and pragmatic factors that contribute to perceptions of fluency.

The finding, that only a small percentage (13.4\%) characterised fluency in a narrow and focused sense was rather surprising since we had assumed language teachers would allude to a narrower and perhaps more focused view of fluency and certainly one which sets fluency apart from complexity and accuracy. Our assumption stemmed from the fact that fluency has for a long time been considered a major component of communicative language ability (Bachman, 1990; CEFR, 2011; Fulcher, 2003; Skehan, 2003, 2009), and a key construct in the assessment of spoken language ability across different language benchmarks (e.g. ACTEFL, 1986; IELTS, 2012) although it has only recently been formally introduced to some national curricula (e.g. 
GCSE syllabus for Modern Foreign languages in the UK, 2015). Furthermore, we note that some teacher training materials (e.g. Harmer, 2005) discuss classroom-based speaking activities with distinctions made between a focus on 'accurate' or 'fluent' L2 speech (e.g. Harmer, 2005; Scrivener, 1994). However, we are also aware that fluency, in this narrow sense of the term, is neither systematically defined nor carefully operationalised in a number of international language tests (Tavakoli, Nakatsuhara \& Hunter, 2017) and teacher training manuals tend to focus on practices related to error correction during speaking activities and offer teachers no specific explanation of fluent speech or any examples of fluency-enhancing activities.

We note that adopting a narrow perspective to fluency can also be constrained by operational limitations or practical concerns. For example, Galcazi, et al. (2013) argue that in examining fluency in speaking tests the priority for language testing research is to strike a balance between "construct coverage", i.e. relatively long and detailed characteristics of fluency, and "examiner usability", i.e. relatively short and succinct descriptors of fluency that can be conveniently used by examiners. This is particularly important in the light of Brown's (2006) findings that suggested IELTS examiners find fluency very difficult to rate. As regards language benchmark documents such as the CEFR, although, in principle, they encourage a narrower perspective to fluency than that demonstrated by the teachers in the current study, and highlight characteristics such as 'smooth flow of language' and the role of pausing, hesitations and reformulations (pp. 28-9), they may not provide teachers with an adequately clear and easy-to-workwith framework for defining fluency and promoting it in the classroom.

The finding that teachers' definitions of fluency are broader than expected is in contrast with Dore (2015) who reported that the UK-based teachers' knowledge of fluency was in line with international speaking test descriptors. We explain the discrepancy in light of the differences between the participants in the two studies. While in Dore's study the participants were all university EAP teachers who were more familiar with formal speaking test descriptors, our teachers came from very diverse backgrounds in terms of their teaching experiences and their familiarity with speaking tests and the corresponding test descriptors.

Our reading of the literature, coupled with the analysis of our data, lead us to suggest that there are at least four different but inter-related approaches to defining fluency (see Figure 1). 
Insert Figure 1 here.

As indicated in Figure 1, at the bottom of the fluency pyramid, we have a very broad perspective in which fluency is defined as a general view of L2 proficiency, and encompasses L2 ability in skills beyond L2 speaking. At this level, fluency may be used synonymously with 'proficiency' in or 'mastery' of the L2. Next we have a broad perspective to fluency. At this level, fluency reflects L2 speaking ability, and as such a fluent person in this sense is someone who can speak confidently and communicate their intended message well in the spoken mode. This definition will incorporate elements of pronunciation, accuracy in speech, and ability to hold a conversation. The third level of definition is a narrow perspective to conceptualising fluency. Fluency in this sense relates to ease, flow and continuity of speech and sets fluency apart from other aspects of oral performance such as grammatical complexity and accuracy. Finally, there is a very narrow perspective to defining fluency, often used by fluency researchers, in which fluency can be objectively measured by examining the speech in terms of its speed, silence and repair.

With regard to our second research question, the data analysis implied that a relatively small proportion (10.4\%) of the activities suggested by the teachers were of the sort that have been identified as fluency-enhancing by research (e.g. Boers, 2014; de Jong \& Perfetti, 2011; Tavakoli, et al., 2016; Thai \& Boers, 2016; Rossiter et al., 2010). It was surprising to see that, despite the evidence for the activities outlined earlier in this paper, they were not frequently referred to in the data. In the absence of any data to explain the mismatch between what fluency research suggests as useful and what the teachers in this study reported as their practice, we can only hypothetically suggest some answers.

One possible explanation is that the teachers were simply not familiar with the activities this body of research has proposed. This hypothesis would provide support for the 'gap' frequently reported between L2 research and its practice (Graham \& Santos, 2014; Nassaji, 2012; Tavakoli, 2015; Tomlinson, 2016; Foster \& Hunter, 2016). Previous research (Borg \& Burns, 2008; Graham, et al., 2014; Nassaji, 2012) has shown that teachers' beliefs and practices are to a large extent reliant on practical and experiential basis rather than on research findings. Studies in teacher research engagement (Han, 2007; Nassaji, 2012; Tavakoli, 2015) have also argued that for teachers to value research 
findings and include them in their practice, research should be accessible, have practical pedagogic implications, and develop ideally in collaboration with teachers. In line with Han's (2007) argument about the usefulness of pedagogic findings in L2 research, we argue that the gap can only be minimised if researchers and language teachers can develop collaborative research from which both parties would benefit.

It is also possible that suggestions and pedagogic recommendations offered by L2 fluency research are not accepted by language teachers. For example, there is some evidence to suggest that, while students value task repetition as a useful classroom activity (e.g. Pinter, 2010; Lambert et al, 2016), language teachers were reluctant to use it in their practice for fear of students finding task repetition 'boring' (Ahmadian et al.; 2017). Further research is clearly needed to test this assumption.

Although the quantitative analysis suggested that the teachers felt reasonably confident in their ability to promote fluency in class, a large majority of the activities proposed were more suited for developing speaking ability in general (free-production activities debates, discussions etc). Interestingly, too, this category was also the most popular activity type of the teaching materials and textbooks Rossiter et al (2010) analysed. As we found that the majority of teachers in this study considered that the term 'fluency' related to all aspects of speaking ability, another interpretation is that free-production activities are popular as they align more with this broader definition of fluency. In other words, if a teacher's understanding of fluency is that it is to do with skill in speaking, it follows that the activities they suggest would be those that simply encourage students to speak. Certainly, L2 research also provides evidence (e.g. DeKeyser, 2007; Johnson, 2004; de Jong \& Perfetti, 2011) that speaking practice aids the proceduralisation of L2 knowledge and automatic use of language. The congruity of the findings between teachers' definitions of fluency and their suggested activities is perhaps evidence to the existence of a "symbiotic relationship" (Foss \& Kleinsasser 1996: 441) between teachers' understandings and their practices. Research in L2 teacher education has already highlighted the importance of the relationship between teacher cognition and their classroom practice (e.g. Borg, 2003). In order for teachers and researchers to communicate they need to have a shared language. We would argue, therefore, that to encourage a more evidence-based approach to L2 teaching practice, teacher training and education programmes can play a crucial role by also discussing definitions of key terms and ideas. 
We acknowledge, however, that many free-production activities, such as roleplays and debates, can be easily "tweaked" to give them a narrower fluency focus (Foster \& Hunter, 2016; Diepenbroek \& Dewing, 2014). We do not know what adaptations the teachers in the current study might make to the free-production activities that they mention. Future studies might, therefore, consider triangulating findings with classroom observations in order to better understand how free-production activities are actually manipulated for teaching purposes.

\section{Conclusions}

Rossiter et al. (2010) referred to fluency as a neglected component in language teaching as the books they investigated relied heavily on generic speaking activities with limited attention to evidence-based, fluency-focused practices. In some ways, our study replicated Rossiter et al.'s (2010), but investigated teaching practice as opposed to teaching materials. Similar to Rossiter et al, we found that there does appear to be a gap between fluency research and language pedagogy. However, the current research also revealed that the majority of the teachers in this study conceive of fluency in a much broader sense than that which is used for research purposes and that teachers are providing students with general speaking practice through the use of free-production activities. By way of a conclusion, then, fluency, in its focused and narrow sense, might very well be neglected in L2 classrooms. We have suggested that there may be a link between teachers' definition of fluency and their classroom practice. More research is needed to develop a clearer picture of why teachers adopt a broad approach to defining fluency and in what ways their understanding of fluency relate to their professional practice. Further research is also required to examine whether there are differences in the ways teachers define and promote fluency with groups of students of differing age and proficiency level. We suggest the findings of the current study are considered cautiously since we acknowledge it is a small-scale study with limitations in its methodology, e.g. relying on self-reported data rather than observations and interviews.

Notwithstanding the value of the existing L2 fluency research, we feel that an insight into how teachers understand fluency will complement the current research-led conceptualisations of fluency. More importantly, to bridge the gap between different disciplines interested in fluency research, e.g. L2 teaching, teacher training, language 
testing and L2 research (to name a few), we argue that understanding the contexts in which these disciplines operate is key to achieving outcomes that are beneficial to all.

\section{References}

ACTEFL (1986) American Council on the Teaching of Foreign Languages. https://www.actfl.org/publications/all/world-readiness-standards-learninglanguages/standards-summary

Ahmadian, M. J. (2012). The effects of guided careful online planning on complexity, accuracy and fluency in intermediate EFL learners' oral production: The case of English articles. Language Teaching Research, 16(1), 129-149.

Ahmadian, M. J., \& Tavakoli, M. (2011). The effects of simultaneous use of careful online planning and task repetition on accuracy, complexity, and fluency in EFL learners' oral production. Language Teaching Research, 15(1), 35-59.

Ahmadian M.J, Mansouri A, Ghominejad S, (2017). Language learners' and teachers' perceptions of task repetition, ELT Journal. Available from:

http://eprints.whiterose.ac.uk/109424/

Bachman, L. F. (1990). Fundamental considerations in language testing. Oxford University Press.

Boers, F. (2014). A Reappraisal of the 4/3/2 Activity. RELC Journal, 45(3), 221-235.

Boersma, P., \& Weenink, D. (2008). Praat: doing phonetics by computer. Version 5.0.40. Available from: http://www.praat.org/.

Borg, S. (2003). Teacher cognition in language teaching: A review of research on what language teachers think, know, believe, and do. Language Teaching, 36(02), 81-109.

Borg, S. (2009). English language teachers' conceptions of research. Applied Linguistics, 30(3), 358-388.

Borg, S., \& Burns, A. (2008). Integrating grammar in adult TESOL classrooms. Applied Linguistics, 29(3), 456-482.

Brown, A. (2006). An examination of the rating process in the revised IELTS speaking test. In P. McGovern \& S. Walsh (Eds.), IELTS Research Report (Vol. 6) (pp. 41-70). Canberra: IELTS Australia \& British Council.

Chambers, F. (1997). What do we mean by fluency? System, 25(4), 535-544.

Council of Europe (2011). Common European Framework of Reference for Languages: Learning, Teaching, Assessment. Council of Europe.

De Bot, K. (1992). Applied linguistics. Applied linguistics, 13(1), 1-24. 
De Jong, N. H. (2016). Predicting pauses in L1 and L2 speech: the effects of utterance boundaries and word frequency. International Review of Applied Linguistics in Language Teaching, 54(2), 113-132.

De Jong, N. H., \& Wempe, T. (2009). Praat script to detect syllable nuclei and measure speech rate automatically. Behavior Research Methods, 41(2), 385-390.

De Jong, N. H., Steinel, M. P., Florijn, A. F., Schoonen, R., \& Hulstijn, J. H. (2012). Facets of speaking proficiency. Studies in Second Language Acquisition, 34(01), 5-34.

De Jong, N., \& Perfetti, C. A. (2011). Fluency training in the ESL classroom: An experimental study of fluency development and proceduralization. Language Learning, 61(2), 533-568.

DeKeyser, R. (2007). Skill acquisition theory. In J. Williams and B. VanPatten (eds.), Theories in second language acquisition: An introduction (97-113), Erlbaum, Mahwah, NJ.

Derwing, T. M., Munro, M. J., Thomson, R. I., \& Rossiter, M. J. (2009). The relationship between L1 fluency and L2 fluency development. Studies in Second Language Acquisition, 31(04), 533-557.

Diepenbroek, L. G., \& Derwing, T. M. (2014). To what extent do popular ESL textbooks incorporate oral fluency and pragmatic development. TESL Canada Journal, 30(7), 1.

Dore, C. (2015). Perceptions of fluency. British Council ELT Master's Dissertation Awards: Winner.

https://englishagenda.britishcouncil.org/sites/default/files/attachments/dissertation desi gn_for_publication_2016_reading_university_cecilia_dore.pdf

Ellis, R. (2009). The differential effects of three types of task planning on the fluency, complexity, and accuracy in L2 oral production. Applied Linguistics, 30(4): 474-509.

Foss, D. H., \& Kleinsasser, R. C. (1996). Preservice elementary teachers' views of pedagogical and mathematical content knowledge. Teaching and teacher Education, 12(4), 429-442.

Foster, P. (2009). Task-based language learning research: expecting too much or too little? International Journal of Applied Linguistics, 19(3), 247-263.

Foster, P., \& Hunter, A. M. (2016). When it's not what you do but the way that you do it. SLA Research and Materials Development for Language Learning (pp. 280-298). London: Routledge.

Foster, P., \& Skehan, P. (1996). The influence of planning and task type on second language performance. Studies in Second language acquisition, 18(03), 299-323.

Foster, P., \& Tavakoli, P. (2009). Native speakers and task performance: Comparing effects on complexity, fluency, and lexical diversity. Language learning, 59(4), 866-896. 
Freed, B. (2000). Is fluency, like beauty, in the eyes (and ears) of the beholder? In Perspectives on fluency (pp. 243-265). Michigan: University of Michigan Press.

Freed, B. F., Segalowitz, N., \& Dewey, D. P. (2004). Context of learning and second language fluency in French: Comparing regular classroom, study abroad, and intensive domestic immersion programs. Studies in second language acquisition, 26(02), 275-301.

Fulcher, G. (2003). Testing second language speaking. Pearson Education.

Galaczi, E., Lim, G. \& Khabbazbashi, N. (2013). Rating Scale development and use: The rater perspective. CRELLA Research Seminars, University of Befordshire.

Gass, S., Mackey, A., Alvarez-Torres, M. J., \& Fernández-García, M. (1999). The effects of task repetition on linguistic output. Language Learning, 49(4), 549-581.

Gatbonton, E., \& Segalowitz, N. (1988). Creative automatization: Principles for prmoting fluency within a communicative framework. TESOL quarterly, 22(3), 473-492.

Gatbonton, E., \& Segalowitz, N. (2005). Rethinking communicative language teaching: A focus on access to fluency. Canadian Modern Language Review, 61(3), 325-353.

Graham, S., Santos, D. \& Francis-Brophy, E. (2014) Teacher beliefs about listening in a foreign language. Teaching and Teacher Education, 40(1), 44-60.

Han, Z. (2007). Pedagogical Implications: Genuine or Pretentious? TESOL Quarterly, 41(2), 387-93.

Harmer, J. (2005). The practice of English language teaching. London/New York.

Housen, A., Kuiken, F., \& Vedder, I. (Eds.). (2012). Dimensions of L2 performance and proficiency: Complexity, accuracy and fluency in SLA (Vol. 32). John Benjamins Publishing.

IELTS (2012). IELTS speaking band descriptors. British Council. http://takeielts.britishcouncil.org/find-out-about-results/ielts-assessment-criteria

Johnson, K. (2004). Language teaching and skill learning. Blackwell.

Kahng, J. (2014). Exploring utterance and cognitive fluency of L1 and L2 English speakers: Temporal measures and stimulated recall. Language Learning, 64(4), 809-854.

Koponen, M., \& Riggenbach, H. (2000). Overview: Varying perspectives on fluency. In H. Riggenbach (Ed.), Perspectives on fluency (pp. 5-24). Michigan: The University of Michigan Press.

Kormos, J. (2006). Speech production and second language acquisition. Mahwah, N.J.: Lawrence Erlbaum

Kormos, J., \& Dénes, M. (2004). Exploring measures and perceptions of fluency in the speech of second language learners. System, 32(2), 145-164. 
Lambert, C., Kormos, J., \& Minn, D. (2016). Task repetition and second language speech processing. Studies in Second Language Acquisition, 1-30.

Lennon, P. (1990). Investigating fluency in EFL: A quantitative approach. Language learning, 40(3), 387-417.

Levelt, W. J. M. (1989). Speaking: From intention to articulation. Cambridge, Mass: The MIT Press

Lynch, T., \& Maclean, J. (2000). Exploring the benefits of task repetition and recycling for classroom language learning. Language Teaching Research, 4(3), 221-250.

Mehnert, U. (1998). The effects of different lengths of time for planning on second language performance. Studies in second language acquisition, 20(01), 83-108.

Mochizuki, N., \& Ortega, L. (2008). Balancing communication and grammar in beginning-level foreign language classrooms: A study of guided planning and relativization. Language Teaching Research, 12(1), 11-37.

Mora, J. C., \& Valls-Ferrer, M. (2012). Oral fluency, accuracy, and complexity in formal instruction and study abroad learning contexts. TESOL Quarterly, 46(4), 610-641.

Nassaji, H. (2012). The relationship between SLA research and language pedagogy: Teachers' perspectives. Language Teaching Research, 16(3), 337-365.

Nation, P. (1989). Improving speaking fluency. System, 17(3), 377-384.

Préfontaine, Y. (2013). Perceptions of French fluency in second language speech production. Canadian Modern Language Review, 69(3), 324-348.

Préfontaine, Y., \& Kormos, J. (2016). A qualitative analysis of perceptions of fluency in second language French. International Review of Applied Linguistics in Language Teaching, 54(2), 151-169.

Révész, A., Ekiert, M., \& Torgersen, E. N. (2016). The effects of complexity, accuracy, and fluency on communicative adequacy in oral task performance. Applied Linguistics. 37 (6): 828-848.

Rossiter, M. J., Derwing, T. M., Manimtim, L. G., \& Thomson, R. I. (2010). Oral fluency: The neglected component in the communicative language classroom. Canadian Modern Language Review, 66(4), 583-606.

Sample, E., \& Michel, M. (2014). An Exploratory Study into Trade-Off Effects of Complexity, Accuracy, and Fluency on Young Learners' Oral Task Repetition. TESL Canada Journal, 31, 23-46.

Scrivener, J. (1994). Learning teaching (pp. 7-13). Oxford: Heinemann.

Segalowitz, N. (2010). Cognitive bases of second language fluency. Routledge. 
Segalowitz, N. (2016). Second language fluency and its underlying cognitive and social determinants. International Review of Applied Linguistics in Language Teaching, 54(2), 79-95.

Seifoori, Z., \& Vahidi, Z. (2012). The impact of fluency strategy training on Iranian EFL learners' speech under online planning conditions. Language Awareness, 21(1-2), 101112.

Skehan, P. (2003). Task-based instruction. Language teaching, 36(01), 1-14.

Skehan, P. (2009). Modelling second language performance: Integrating complexity, accuracy, fluency, and lexis. Applied linguistics, 30(4), 510-532.

Tavakoli, P. (2015). Connecting research and practice in TESOL: A community of practice perspective. RELC Journal, 46(1), 37-52.

Tavakoli, P. (2016). Fluency in monologic and dialogic task performance: Challenges in defining and measuring L2 fluency. International Review of Applied Linguistics in Language Teaching, 54(2), 133-150.

Tavakoli, P., \& Skehan, P. (2005). Strategic planning, task structure, and performance testing. Planning and task performance in a second language, 11, 239-273.

Tavakoli, P., Campbell, C., \& McCormack, J. (2016). Development of speech fluency over a short period of time: Effects of pedagogic intervention. TESOL Quarterly, 50(2), 447 471.

Tavakoli, P., Nakatsuhara, F. \& Hunter, A. (2017). Scoring validity of the Aptis Speaking test: Investigating fluency across tasks and levels of proficiency. Aptis Final Report. British Council.

Thai, C., \& Boers, F. (2016). Repeating a Monologue under Increasing Time Pressure: Effects on Fluency, Complexity, and Accuracy. TESOL Quarterly, 50(2), 369-393.

Tomlinson, B. (Ed.). (2016). SLA Research and Materials Development for Language Learning. London: Routledge.

Wang, Z. (2014). Developing accuracy and fluency in spoken English of Chinese EFL learners. English Language Teaching, 7(2), 110-136.

Wood, D. (2010). Formulaic language and second language speech fluency: Background, evidence and classroom applications. Bloomsbury Publishing.

Wood, D. (2016). Willingness to communicate and second language speech fluency: An idiodynamic investigation. System, 60, 11-28.

Wray, A. (2000). Formulaic sequences in second language teaching: Principle and practice. Applied linguistics, 21(4), 463-489.

Wray, A. (2002). Formulaic language in computer-supported communication: theory meets reality. Language Awareness, 11(2), 114-131. 
Wray, A. (2008). Formulaic language: Pushing the boundaries. Oxford University Press.

Acknowledgement: We are very grateful to Colin Campbell and Joan McCormack for their endless help and support in setting up the project, and to all the teachers who completed the questionnaires. We thank Language Teaching Research editors and two anonymous reviewers for their invaluable feedback on an earlier draft of the article.

Table 1: Teachers' understanding of speech fluency

\begin{tabular}{|l|c|c|c|c|}
\hline & $\begin{array}{c}\text { To a } \\
\text { large } \\
\text { extent } \\
(\%)\end{array}$ & $\begin{array}{c}\text { To } \\
\text { some } \\
\text { extent } \\
(\%)\end{array}$ & $\begin{array}{c}\text { To a } \\
\text { limited } \\
\text { extent } \\
(\%)\end{array}$ & $\begin{array}{c}\text { Hardly } \\
\text { at all } \\
(\%)\end{array}$ \\
\hline I know what L2 speech fluency means & 19.0 & 64.3 & 16.7 & 0 \\
\hline I know what factors contribute to speech fluency & 11.9 & 59.5 & 27.4 & 1.2 \\
\hline
\end{tabular}

Table 2: Teachers' definitions of L2 fluency

\begin{tabular}{|l|c|c|l|}
\hline $\begin{array}{l}\text { Categories of L2 } \\
\text { fluency definitions }\end{array}$ & Frequency & $\%$ & \multicolumn{1}{|c|}{ Examples from the data } \\
\hline $\begin{array}{l}\text { Fluency (in a narrow } \\
\text { sense) }\end{array}$ & 61 & 13.4 & $\begin{array}{l}\text { lack of hesitation, speed, fluidity, } \\
\text { infrequent pauses }\end{array}$ \\
\hline Speaking ability & 198 & 43.8 & $\begin{array}{l}\text { speaking confidently, conveying the } \\
\text { intended meaning, ability to have a } \\
\text { conversation; good pronunciation }\end{array}$ \\
\hline General L2 proficiency & 147 & 32.5 & $\begin{array}{l}\text { ability to paraphrase; a wide range of } \\
\text { vocabulary; cultural understanding; } \\
\text { correct use of grammar; good } \\
\text { understanding of language }\end{array}$ \\
\hline $\begin{array}{l}\text { Vague or uninformative } \\
\text { terms }\end{array}$ & 46 & 10.2 & $\begin{array}{l}\text { not so much of body language, read } \\
\text { classic literature; school experience }\end{array}$ \\
\hline
\end{tabular}

$N=84 ; n=452$

Table 3: Teachers' confidence in promoting fluency in classroom

\begin{tabular}{|l|c|c|c|c|}
\hline & $\begin{array}{c}\text { To a } \\
\text { large } \\
\text { extent } \\
(\%)\end{array}$ & $\begin{array}{c}\text { To } \\
\text { some } \\
\text { extent } \\
(\%)\end{array}$ & $\begin{array}{c}\text { To a } \\
\text { limited } \\
\text { extent } \\
(\%)\end{array}$ & $\begin{array}{c}\text { Hardly } \\
\text { at all } \\
(\%)\end{array}$ \\
\hline $\begin{array}{l}\text { I know how speech fluency can be taught in L2 } \\
\text { classroom }\end{array}$ & 10.7 & 41.7 & 39.3 & 8.3 \\
\hline $\begin{array}{l}\text { I know how to help my learners improve speech } \\
\text { fluency }\end{array}$ & 8.3 & 47.6 & 36.9 & 7.1 \\
\hline $\begin{array}{l}\text { I know the kind of activities that help promote } \\
\text { speech fluency }\end{array}$ & 10.8 & 48.2 & 38.6 & 2.4 \\
\hline $\begin{array}{l}\text { I know learning strategies that help learners } \\
\text { improve their L2 speech fluency }\end{array}$ & 9.5 & 51.2 & 31 & 8.3 \\
\hline
\end{tabular}




\begin{tabular}{|l|c|c|c|c|}
\hline $\begin{array}{l}\text { I feel confident about helping my learners improve } \\
\text { their speech fluency }\end{array}$ & 23.8 & 45.2 & 28.6 & 1.2 \\
\hline
\end{tabular}

Table 4: Teachers' familiarity with fluency research

\begin{tabular}{|l|c|c|c|c|}
\hline & $\begin{array}{c}\text { To a } \\
\text { large } \\
\text { extent } \\
(\%)\end{array}$ & $\begin{array}{c}\text { To } \\
\text { some } \\
\text { extent } \\
(\%)\end{array}$ & $\begin{array}{c}\text { To a } \\
\text { limited } \\
\text { extent } \\
(\%)\end{array}$ & $\begin{array}{c}\text { Hardly } \\
\text { at all } \\
(\%)\end{array}$ \\
\hline $\begin{array}{l}\text { I know recent research findings about how to } \\
\text { promote speech fluency }\end{array}$ & 39.3 & 20.2 & 4.5 & 33.3 \\
\hline $\begin{array}{l}\text { I think recent research in speech fluency can help } \\
\text { me with my classroom teaching practice }\end{array}$ & 39.3 & 33.3 & 19 & 8.3 \\
\hline
\end{tabular}

Table 5: Activities the teachers reported to use to promote fluency in classroom

\begin{tabular}{|c|c|c|c|}
\hline $\begin{array}{l}\text { Categories of fluency- } \\
\text { focused activities }\end{array}$ & $\begin{array}{c}\text { Fre } \\
\text { q }\end{array}$ & $\%$ & Examples from the data \\
\hline Consciousness-raising & 4 & 1.6 & $\begin{array}{l}\text { Asking students to listen to their recorded } \\
\text { performance; making them aware of the } \\
\text { importance of uninterrupted speech }\end{array}$ \\
\hline $\begin{array}{l}\text { Planning, rehearsal and } \\
\text { repetition }\end{array}$ & 7 & 2.8 & $\begin{array}{l}\text { Surveys around the room by repeating the } \\
\text { same speaking activity; Give students one } \\
\text { minute to plan before they perform a task, } \\
\text { and ask them to repeat it. }\end{array}$ \\
\hline $\begin{array}{l}\text { Formulaic language, } \\
\text { discourse markers and } \\
\text { lexical fillers }\end{array}$ & 8 & 3.2 & $\begin{array}{l}\text { Teaching and practicing lexical chunks; } \\
\text { memorising prefabricated chunks }\end{array}$ \\
\hline $\begin{array}{l}\text { Fluency strategy } \\
\text { Training }\end{array}$ & 7 & 2.8 & $\begin{array}{l}\text { Introducing fillers as a strategy; repair } \\
\text { strategies }\end{array}$ \\
\hline $\begin{array}{l}\text { Communicative free } \\
\text { production activities }\end{array}$ & 135 & 53.6 & $\begin{array}{l}\text { Role-plays, debates, pair and group work, } \\
\text { information-gap activities; conversations }\end{array}$ \\
\hline General L2 proficiency & 34 & 13.5 & $\begin{array}{l}\text { Listening to native speakers; practicing } \\
\text { listening, reading and writing; vocabulary } \\
\text { learning; translation }\end{array}$ \\
\hline None & 57 & 22.6 & No examples provided by the teachers. \\
\hline
\end{tabular}

$N=84 ; n=252$ 


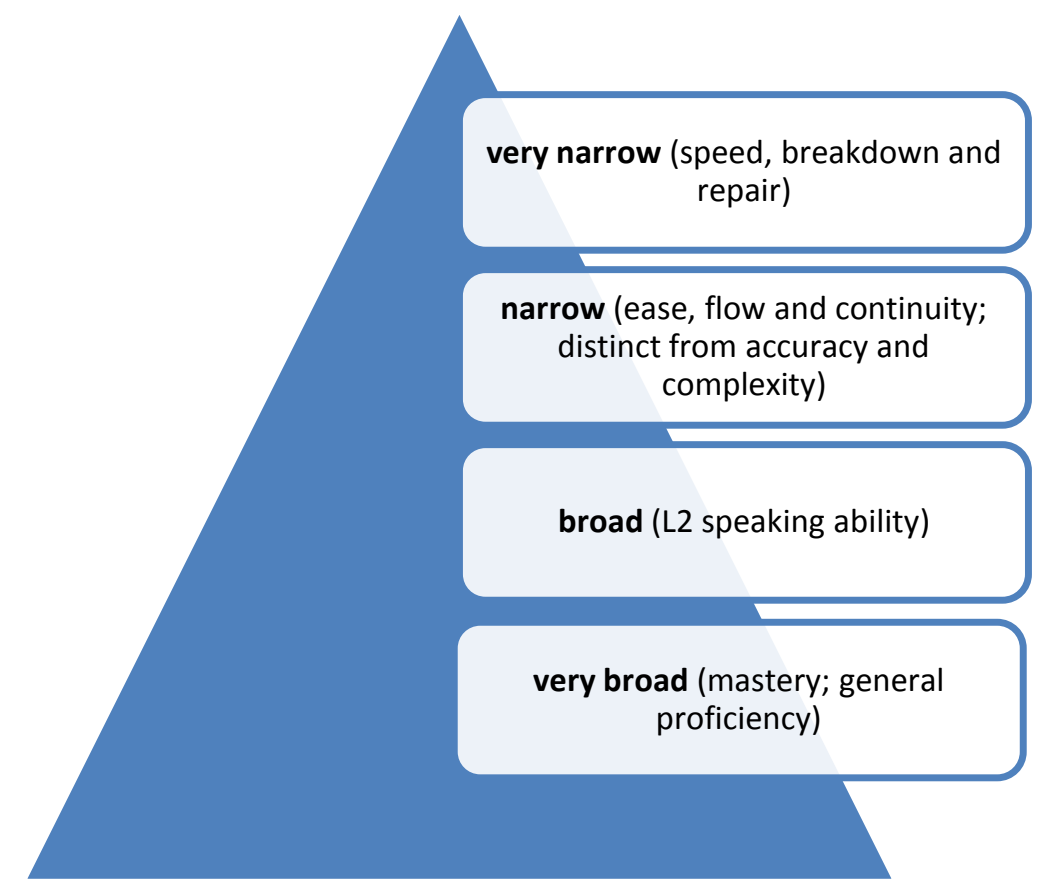

Figure 1: Four approaches to defining fluency 